\title{
Risk-Layering for Indirect Effects
}

\author{
Stefan Hochrainer-Stigler ${ }^{1} \cdot$ Karina Reiter $^{1}$
}

Accepted: 25 August 2021 / Published online: 8 September 2021

(C) The Author(s) 2021

\begin{abstract}
Environmental risks are one of the greatest threats in the twenty-first century. Especially in the last years, the cascading impacts and risks associated with such events have received great attention as economic losses and consequences have mounted in their wake. As concerns about these ripple effects are rising, strategies to prevent and manage indirect risks are in urgent demand. However, such effects are currently barely considered in most countries and can seriously threaten global agendas such as achieving the Sustainable Development Goals by 2030 or the targets set out in the Sendai Framework for Disaster Risk Reduction 2015-2030. We discuss how the concept of risk-layering, which, though already applied in disaster risk management, could be expanded to include indirect effects. We point out some of the benefits, limitations, and ways forward for using this approach. To do so, we first delineate the transition of the risk-layering concept, which originated from the insurance industry, from its original use to its application in a wider context. We bring special focus to the application of risk-layering in disaster risk management and identify strategies that allow for the inclusion of indirect risks. Our main suggestion is that, while a probabilistic approach is appropriate for evaluating direct risks, a focus on connectedness is appropriate for indirect risks, which still allows for an easy link to direct risklayering. This, so we argue, facilitates more comprehensive risk management systems apt to deal with the multi-dimensional challenges ahead.
\end{abstract}

Stefan Hochrainer-Stigler

hochrain@iiasa.ac.at

1 IIASA - International Institute for Applied Systems Analysis, A-2361 Laxenburg, Austria
Keywords Connectedness - Indirect risks - Natural hazards and disasters · Risk-layering · Risk management

\section{Introduction}

Disaster risks related to natural hazards are one of the greatest threats in the twenty-first century (World Economic Forum 2021) putting political, social, and economic systems increasingly under pressure and at risk of instability (Burke et al. 2015; Carleton and Hsiang 2016; Lamperti et al. 2019). Especially in recent years, the cascading impacts and risks associated with such events have received great attention as economic losses and consequences have mounted (World Economic Forum 2019; UNDRR/CRED 2020). In addition to a change in frequency and intensity of extreme weather events and the rising accumulation of assets in risk areas (Schipper et al. 2016; Blöschl et al. 2019; Aon 2020), more interconnected and complex economic networks and production chains are at fault for these developments (Centeno et al. 2015; Lucas et al. 2018; Zscheischler et al. 2020). As a result, natural hazards and disasters can cause ripple effects along supply chains causing business or supply chain interruptions, a change in economic productivity following a disaster or increased indebtedness (Hallegatte and Przyluski 2010). These so called indirect losses can amount to or even surpass direct damages (Koks et al. 2015; Dottori et al. 2018).

As concerns about these ripple effects are rising, especially in the context of compound events (that is, combinations of multiple climate drivers and/or hazards), strategies to prevent and manage indirect risks are in urgent demand (Zscheischler et al. 2020). However, such effects are currently barely considered in most countries' risk 
management plans even though they can seriously threaten global agendas such as achieving the Sustainable Development Goals by 2030 (Reichstein et al. 2021) or targets formulated in the Sendai Framework for Disaster Risk Reduction 2015-2030. While the need for new partnerships is forming (Bucher et al. 2020) (for example, codesigning strategies, that is including stakeholders from the very beginning of the research) to effectively deal with disasters (Shaw 2020), the major focus of traditional risk management still lies on combating the direct effects of disasters. This can be explained partly with the fact that direct risk management, by definition, also reduces the chances of indirect risks, as the latter emerges merely in association with the former (Lucas et al. 2018). The fact that indirect damages prove especially difficult to be assessed and modelled (Hallegatte 2015; Botzen et al. 2019) adds further obstacles to their active integration in disaster risk management. Nevertheless, ways forward, both conceptually and methodologically, are in desperate need (Shi et al. 2020). In this context, we discuss here how the concept of risk-layering, though already having been applied in disaster risk management for quite some time (Mechler et al. 2014), could be expanded to include indirect effects as well. In doing so, we point out some of the benefits, limitations, and ways forward for using this approach. Our main suggestion is that indirect risk and more traditional direct risk-layering approaches can be linked if adapted correspondingly. This, we argue, would allow for more comprehensive risk management systems apt for dealing with the multilayered challenges of the twenty-first century.

In laying out these arguments in what follows, we first delineate the transition of the risk-layering concept, which originated from the insurance industry, from its original use to its application in a wider context (Sect. 2). Then, we bring into focus the application of risk-layering in disaster risk management and identify strategies that allow for the inclusion of indirect risks in disaster risk management (Sect. 3). Finally, Sect. 4 summarizes our findings and provides an outlook for the future.

\section{Direct Risk and the Use of Risk-Layering}

The following discussion is based on a review of relevant literature, spanning from research articles to grey literature and official websites/homepages to investigate in which disciplines risk-layering is currently used as a concept and how. Our search was carried out using the search terms "risk-layer*" and "layer* of risk" on Scopus, GoogleScholar, and, for websites and homepages, google.com. The asterisks were used as wildcards to find variations of the exact phrases. Additionally, we used a snowballing approach to find other relevant publications on the subject based on publications already reviewed and added them to the existing collection. Publications thus found spanned a variety of research fields, from economics and finance to environmental science as well as social science and medicine. However, the field of environmental science was most frequently represented. We gathered information about the risk-layering concept and its original usage, how its understanding was expanded to other disciplines, and how it is currently being implemented. The findings from this literature are presented in the following section.

\subsection{The Origins in Insurance}

The concept of risk-layers, or risk-layering, has its origins in the insurance industry and is a key practice in risk management. It is a type of non-proportional reinsurance, that is, a risk transfer procedure that is based on loss retention. Insurance cover is provided by a ceding insurer up to a predetermined level, after which, following the excess of loss approach, a risk transfer chain is formed where co-insurer(s) compensate(s) the primary insurer for losses exceeding the predetermined level (Bugmann 1997). Thus, risk is split into several parts, or layers, where each layer is covered up to a defined limit by the respective insurer. In other words, the insured risk is retained by the primary insurer until a predefined limit. If this limit is surpassed, the risk is transferred to the subsequent insurance company (this is also referred to as attachment point), which in turn provides coverage until a predefined limit (also referred to as exhaustion point (Andersen 2011)). Following this principle, chains of excess-of-loss insurances develop, where each layer of risk is covered by a different insurance agent which, ultimately, allows for high insurance cover. Risk-layers represent the level of potential losses and the probability at which they occur, that is, the "bottom" risk-layers comprise low loss levels with high probability of occurrence while "top" risk-layers cover high but rare loss levels (Fig. 1). Insurance programs following a risk-layering concept are typically implemented when large, unbalanced risks are involved.

The concept of risk-layering has found wide application in the field of risk research and, since risk-layering is especially useful for managing major risks, the concept lends itself especially in the context of natural hazard-related disasters. There, it has been integrated in large areas of risk management policy, first and foremost in the agricultural and insurance market (Stone 1973). As a result, risk-layering has become a typical form of reinsurance cover against catastrophe events, such as floods, hail, frost and droughts, earthquakes, volcanic eruptions, or nuclear accidents (Froot 2001). In addition to private households, farmers, businesses, companies, and insurers seeking re- 
Fig. 1 Risk-layers and associated probability and loss levels. Source Ghesquiere and Mahul (2010).

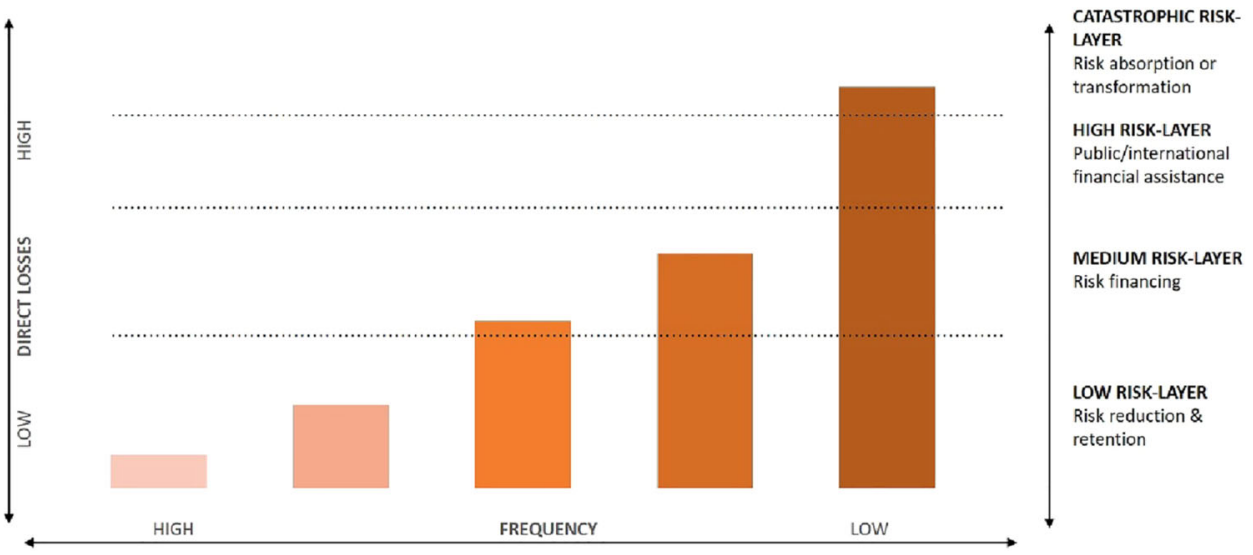

insurance themselves, insurance against such risks is of interest especially to governments, as they function as providers of ex-post disaster relief (Froot 2001; Arias Carballo et al. 2013; Carter et al. 2014; Hochrainer-Stigler and Hanger-Kopp 2017).

\subsection{Risk-Layering in Disaster Risk Management}

The risk-layering concept provides an integrative framework by, similar to the example described above, striking a balance between retaining certain risk-layers and ceding higher ones. To do so, risks are organized into layers according to probabilities/return periods and associated loss levels. For each of these risk-layers, different (combinations of) risk management instruments devised by different actors provide the most suitable management option (Garcia Azcarate et al. 2016). In other words, risklayering can help define a variety of different mechanisms that are strategically put in place for each risk-layer to guarantee efficiency and reduction of risk financing costs (Chantarat et al. 2008; Linnerooth-Bayer and HochrainerStigler 2015). In the case of disaster risk management, a risk-layer approach could take the following form: Four risk-layers and respective sets of management instruments for each layer are identified (Mechler et al. 2014). For low risk-layers (that is, low-impact, high-frequency risks), risk reduction and risk retention activities are most appropriate. Risk reduction activities include structural measures, for example, building codes, grey infrastructure, or land use planning and non-structural measures such as policies, laws, or education programs. Risk retention measures, meanwhile, include drawing upon reserves/savings or contingent credit. For medium risk-layers, a combination of risk reduction and risk-financing instruments, such as disaster (re)insurance programs, public-private partnerships and credits is identified as most suitable. In the case of high risk-layers (that is, high-impact, low-frequency risks), financial assistance from the public sector and international donors is required. For catastrophic risk-layers, even with the help of such domestic or international donations, costs might not be manageable, indicating adaptation limits and calling for transformational changes and policy responses (Deubelli and Mechler 2021). Depending on the type of risk and region/country-specific idiosyncrasies, the thresholds between these layers might differ and, thus, adaptations might be required, see, for instance, suggestions regarding risk-layering in the management of drought and flood risk (Hochrainer-Stigler and Pflug 2012; Schinko et al. 2017), earthquake risk (Sadeghi et al. 2015), risk of harsh winters (Mahul and Skees 2007), or the risk of nuclear accidents (Ayyub et al. 2016).

\subsection{Risk-Layering in Other Disciplines}

Not only in the insurance industry and disaster risk management has the concept found application, but also in numerous other disciplines has the concept been adopted, albeit often in a less well-developed form. In addition to a similarity in the use of the idea of layered risk, that is that various layers of risk are identified, the applications of the concept across disciplines resemble one another in that different treatment or intervention strategies are especially devised for and/or applied to them. This implies that each risk factor needs its own management method and agent under whose responsibility it falls. In medical journals, for instance, the term risk-layer(s)/layer(s) of risk is used when describing the accumulative effect of certain risk factors that increase the likelihood of a particular medical condition to develop. The concept of risk-layers is, for example, used in the context of research on cancer (Yuan et al. 2017; Cha et al. 2018), diabetes (Phillips 2020), HIV (Baral et al. 2013), asthma (Mutius and Smits 2020), or the effect of gambling on public health (Reynolds 2019). In Baral et al. (2013), for instance, five layers of risk are identified and entered into a modified social ecological model (MSEM) for epidemiologic HIV studies. Cha et al. (2018) 
assigned patients to different risk-layers depending on the size of the tumor they are diagnosed with and, based on their findings, suggest a risk stratification model as a prognostic model for breast cancer patients. Dawson and McCulloch (2005) define procedures to combat fatigue related incidents by identifying management options for each layer of risk.

The terms risk-layer(s)/layer(s) of risk are similarly used in social sciences when describing factors facilitating the emergence of emotional or social stress. Blair (2009), for instance, researched the layers of risk involved with respect to the emotional well-being of students with special needs in the classroom. In a similar vein, Giordano and Copp (2015) studied the impact of maternal incarceration as one layer of an entire "package" of risks threatening children's well-being and discuss methods to combat such developments. Farvid and Braun (2018) address identity as a risklayer for one's social, psychological, or physical health when engaging in casual heterosexual intercourse but also refer to the "careful and localized management" it requires. Similarly, DiValli and Perkins (2020, p. 3) refer to "the layers of government interventions" needed to combat climate change induced risks to people's social capital and connectivity in urban areas in the United States.

The exacerbating role of climate change in a range of risks is highlighted in a paper in environmental science by Popp et al. (2009). There, climate change is identified as "additional layer of risk" to already existing pressures on ecosystems while strategies to foster climate change adaptation are highlighted that allow for sustainable resource management (Popp et al. 2009, p. 701). Boyland et al. (2019, p. 182) ascribe a similar role to climate change ("the layer of risk that climate change adds to disaster risks"). According to them, climate change constitutes an added risk-layer in the context of biological offsetting and call on "recovery actors [to] take account of these changing risks in their approaches" (Boyland et al. 2019, p. 182). Summarizing, the term risk-layer is used in many disciplines, for example either for risk management interventions, the pre-disposition of being negatively affected, or simply as additional risk. However, up-to-now it is not yet used in the context of indirect risk and its management (with some important exceptions, for example, insurance for business interruptions (Rose and Huyck 2016)). How this could be done, we discuss next.

\section{Risk-Layering for Indirect Risks}

In the following section, we restrict our discussion to how risk-layering can be adapted to indirect effects in the context of natural hazard-induced disaster risk management. As was already indicated above, risk-layering usually requires the quantification of risk, ideally in the form of a loss distribution, which relates losses to probabilities and which forms a natural linkage to risk-layering (Fig. 1). We therefore further restrict our attention to quantifiable approaches and assume that such loss distribution can (in principle) be estimated. Hence, we neglect various other important disaster related loss dimensions, such as loss of life, quality of life, psychological effects, or other intangible damages, which are important to be considered for integrated disaster risk management purposes. We discuss this issue in more detail in the concluding section. Loss distributions are usually calculated either using past events or through catastrophe risk models (Grossi and Kunreuther 2005). Applying the risk-layering approach, different risk management options are selected for the respective probability levels as is done by, for example, insurance providers when determining when to cede risks, or by governments when determining appropriate risk reduction and risk financing options (Fig. 1, right hand side). Our goal in this section is to provide a similar line of reasoning for indirect risks and the risk-layer concept using connectedness instead of losses as the main linkage.

\subsection{Risk-Layering and Connectedness}

In contrast to direct risk, where only the elements exposed to natural hazards need to be looked at, the hazards' effects experienced beyond these areas and elements must be considered when assessing indirect risk (Naqvi et al. 2020). To achieve this, a systems perspective is beneficial and, in this case, we suggest defining a system to be a set of interconnected elements within a defined system boundary (Hochrainer-Stigler et al. 2020b). The advantage of this definition is, firstly, that it creates clear borders of what a system comprises and what it does not. Secondly, its emphasis lies on the elements of the system that are the reason for indirect effects that ripple through the system. Thirdly, it focuses on the connection between elements necessary for indirect effects to be produced. Note that the system boundary may be different depending on the decision maker in question, that is boundaries differ for insurance providers (for example, exposed assets at risk), a finance ministry (for example, all economic actors of the country), or global policy makers (for example, people, assets, other ecological entities, and so on). For natural hazards, the assessment of asset losses usually only considers elements that are exposed to this particular hazard (for example, the system only includes elements that are exposed to risk) and the corresponding risk-layer only addresses these elements (Grossi and Kunreuther 2005). For indirect risks, however, additional elements that can be affected through different transition channels have to be 
included (Rose et al. 2016). For example, while the system boundary for insurance is only the assets that can be damaged due to natural hazards, the economic consequences may include all elements (for example, households, firms, banks) indirectly affected due to the connectedness among the elements. Hence, defining clear system boundaries separately for risk-layering for indirect risks and for direct risks is essential as they might differ substantially (Naqvi et al. 2020).

Following the classic definition of risk being a function of the hazard, exposure, and vulnerability (IPCC 2012), there is no direct risk without vulnerability of the elements in a system. Hence, if the elements within a system are not potentially able to fail, there are also no indirect risks. Thus, indirect risks can only emerge in the presence of direct risks. As risk-layering for direct risk only includes elements at risk, it can be used as an input for risk-layering for indirect ones, where the system boundary for direct risk is usually a subset of the system boundary for indirect risk. In other words, the elements that can fail (that is, experience losses) are also part of the elements that will trigger indirect effects, including consequences outside the system element's definition for direct risk. However, if there is no connectedness between the elements in the system, there is also no risk of indirect effects. Consequently, system boundaries, the elements in the system and their possibility to fail, as well as the connection between the system elements are key ingredients for an indirect risk-layer approach (see for a similar discussion on direct risk, Shi et al. 2020).

How and why individual failures can cascade through a system are questions that are at the heart of systemic risk research. Many measures have been suggested for assessing elements in the system that are, from a system perspective, either too big to fail, too interconnected to fail, or too important to fail, and so on (see Hochrainer-Stigler et al. 2020b for an overview). Irrespective of how different these measures are, the connectedness between the individual elements in the system lies at the center of most of them (Poledna et al. 2017). Therefore, we argue that the connectedness of the system elements should be a key feature for a risk-layer approach for indirect risk. In more detail, similar to probability changes and corresponding loss levels in the risk-layer approach for direct risk (Fig. 1), the increase in connectedness and its cause for increases in indirect loss levels can be used, which allows for the adaption of the risk-layer concept for indirect risk (Fig. 2). For clarification purposes we want to note that while natural hazard-related disaster events cause direct losses and, therefore, represent pure downside risk (for example, disasters only destroy), it is possible for natural hazards and disasters to have positive indirect effects on the economy. However, we argue to only include negative indirect effects in the analysis as natural hazard-related disasters and possible positive indirect effects cannot be planned for management purposes on the system level (simply as such disasters first cause losses randomly). While we acknowledge that destruction caused by natural hazards and disasters may open up windows of opportunities for building back better, we argue for the overall management goal to be to reduce negative effects as much as possible.

The term connectedness is ambiguous but serves the purpose here as, indeed, it can be defined and assessed by different measures, such as Copulas (for example, strength of connection), DebtRank (for example, centrality of connected elements), proportion of total elements affected, and so on. The measure used ultimately depends on the research question at hand and, therefore, must be chosen case specific (for possible measures of connectedness we refer to Hochrainer-Stigler et al. 2020b). For studying a real-world system, usually the connectedness is modelled and calibrated based on empirical data. Different methods exist in that regard including econometric approaches, CGEs (Computable General Equilibrium), as well as ABMs (Agent-Based Modeling) (see for a review Botzen et al. 2019). As ABMs are especially useful for analyzing cascading, non-linear, and emergent behavior within our systems perspective, and also due to the recent interest in it (see, for example, Reichstein et al. 2021), the next section focuses on practical ways forward on how to connect direct risk-layers with indirect risk-layering using ABMs following our suggested ideas (for other approaches see Botzen et al. 2019).

\subsection{Using Agent-Based Modeling (ABMs) for Establishing Indirect Risk-Layers}

Our starting point is the assumption that risk information is available on the system level in the form of a loss distribution. This could take the form of, for example, damages and corresponding probabilities being made available on the country level by using catastrophe modeling approaches. A risk-layer approach using such loss distributions is, as discussed, quite common today and already applied in various fields (IDB 2014; Hochrainer-Stigler et al. 2021). Information gained in the course of a recent study that investigated the status of direct risk assessment and risklayering for direct risk in Austria (Schinko et al. 2017) using the aforementioned loss distribution approach (see Fig. 1) could, for instance, be used as an input for assessing indirect risks. Austria serves well as a case study as it has a highly advanced flood risk management plan in place. It is first and foremost assets in the proximity of rivers that are affected by flood hazards in Austria (see maps of flood zones for floods with 30-, 100-, and 300-year return periods, downloadable at https://geometadatensuche.inspire.gv. 
Fig. 2 Risk-layers and associated connectedness, loss levels, and management options

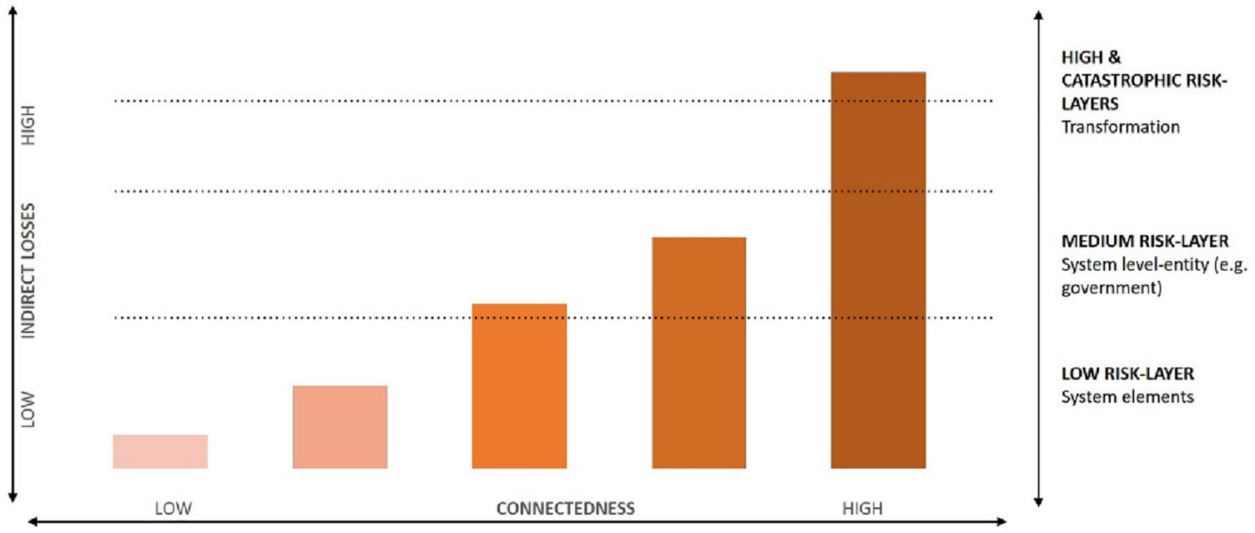

at). These assets located along the river system can be seen as part of the system for direct risk while the whole economic system, including all sectors and entities, form the system for indirect risk. For the ABM approach, the losses for each risk-layer on the country level (Fig. 1) have to be distributed among the elements within the system accordingly, for example by allocating the losses to the exposed assets using hazard maps. Afterwards, the connection between these elements exposed to hazards and other system elements have to be established. Poledna et al. (2018), for example, used an ABM approach to do so and modeled the country-wide effects for Austria for different magnitudes of direct losses following flood events-which could, in a further step, be related to the risk-layers identified in Schinko et al. (2017). Poledna et al. (2018) found that interaction effects can be seen as quite different for each risk-layer with even some systemic risk realizations emerging following the rebuilding of lost assets after the floods due to quite complex mechanisms in place. Importantly, while no or positive effects were found for some layers, the detailed analysis of the elements of the system showed that there are indeed "winners" and "losers" who are not identifiable through aggregate measures such as GDP growth. Such distributional effects could be incorporated within a risk-layer approach, which can, in turn, be linked to management options tailored to the needs and realities of the agents affected.

The ABM model above looked at just one dimension of indirect effects (for example, economic ones) and one type of natural hazard (floods). However, a similar approach could be applied to other hazards, such as drought events, compound events, and different dimensions of indirect effects as well. For example, in Naqvi et al. (2020) a loss distribution for yield losses for certain states in India were estimated and used to shock the respective elements, farmers and agricultural labor, in the system. A two-layer network ABM approach was used, which made it possible to assess effects also outside the agricultural sector, namely displacement and consequences of displacement on prices in other regions. Hence, here too, risk-layering could be implemented to analyze indirect effects on a very detailed level and identify individual management options for each risk-layer. Summarizing, one could use classic catastrophe modeling in combination with ABM to derive a loss distribution for risk-layering, that is, to estimate indirect effects for specific risk-layers and to define ways forward with respect to how to deal with these risks. In this way, individual and systemic indirect effects can be estimated for each risk-layer (such as depicted in Fig. 2) and policy implications determined as discussed next.

\subsection{Policy Implications of Indirect Risk-Layering}

From our systems perspective, the increase in indirect risk can be related to the connectedness of the elements of the system. In this context, Pflug and Pichler (2018) suggested that the system level should bear the costs of such an increase in risk due to an increase in connectedness, for example, bear the costs defined as the difference between the connected and fully unconnected system. Also other authors suggest that major risks due to interconnectedness of system elements have to be dealt with on the system level, for example by governments or respective global policy makers (Poledna and Thurner 2016; Handmer et al. 2020). However, it was also mentioned that indirect effects can be reduced, up to some point, through decrease in individual failures, by the system elements. Hence, both system elements as well as the system itself play an important role in regard to risk-layering and appropriate management of it-as is the case in comprehensive disaster risk management in general (Schinko et al. 2017).

Based on our previous discussion, we suggest that for the low indirect risk-layer, consequences may be small and can be coped with either by the individual elements themselves or by assistance for very vulnerable groups within the system (for example households with few 
resources who are dependent on outside assistance after disasters, or else, may fall into a poverty trap) (Fig. 2). For the medium risk-layer, the government may want to focus on the most influential connections between the system elements or (similar to the case for direct risk) insurance can play a major role (for example, insurance for business interruption). A compulsory natural catastrophe insurance program, for instance, could alleviate flow-on effects following business interruptions and would, according to an Austrian insurance provider, allow for extended insurance cover and more affordable premiums. For the very high loss and connectedness levels, this can be seen either as residual risk or risk that needs transformation to get rid of, for example, systemic risk (Fig. 2). Poledna and Thurner (2016) showed how a systemic risk tax could decrease banking risk to zero. Especially with respect to shifting risks in the future (for example, due to changes in the hazard, exposure, or vulnerability components of a system), risk-layering can be helpful as it goes beyond identifying risk management options for average or expected losses (see Fig. 1) and therefore is also able to identify most important drivers of the increase in specific risks (for example, increase of losses in the high-risk layer due to climate change) (Schinko et al. 2019). The same can be said for risk-layering for indirect risks and the incorporation of possible future dynamics, for example changes in risk-layers due to changes in the connectedness of the system in the future. Therefore, this approach lends itself for determining risk management options that promote efficiency and economic, social, and environmental sustainability - as well as for highlighting the adaptation limits of risk management just as in the case of direct risk management (Mechler et al. 2014).

It should be stressed again that the risk measure for connectedness also influences the management options that can be used and is therefore case specific. We suggest establishing a toolbox approach to analyze connectedness from various angles so that the limitations of one measure are outweighed by introducing another measure that can give a more comprehensive picture (Page 2015; Hochrainer-Stigler et al. 2020a).

\section{Conclusion}

In light of the ever increasing complexity and interconnectedness of economic networks (OECD 2003), the interdependencies of climate change risks, and the ripple effects expected in human and physical systems in response to climate change impacts (Zscheischler et al. 2018), more holistic and long-term approaches in disaster risk management are needed in the future. We argue for an expansion of the risk-layering concept to indirect disaster risk management as one way forward for achieving this goal.

While a probabilistic approach may be appropriate for direct risk-layering, a focus on connectedness is suggested to be appropriate for indirect risk-layering. Connectedness can be assessed using different measures suggested in the literature, for example focusing on the proportion of elements affected or how many elements are too big to fail, or too interconnected to fail, and so on. The measure used itself ultimately depends on the research question at hand and should be chosen case specific. Furthermore, a system approach is essential for indirect risk management, which requires that the system is appropriately defined-a task that is already quite complex but nevertheless necessary for any kind of such an analysis. To add dimensions and complexity, systems of systems may be constructed, but the basic setup for a risk-layer approach remains, that is, the clear definition of what is inside the system and what is not. As discussed, ABM approaches seem especially well suited to explicitly model the indirect effects both from an individual (for example, elements in the system) as well system level perspective and we suggested ways forward on how ABMs can be integrated within direct risk-layering approaches to be used for indirect risk-layering.

Finally, while especially in systemic risk research, the emphasis on connectedness within a system is key, the inclusion of human agency and its adaptive behavior can still be not explicitly included with many challenges ahead (Hochrainer-Stigler et al. 2020a). This is also true for risklayering of indirect risks where social dimensions and adaptive behavior should be explicitly included. In that regard we suggest that in the meantime iterative approaches will work best in practice as a constant updating of a rapidly changing environment can be achieved and emerging problems, short- and long-term, can be monitored, assessed, and eventually managed. In that regard, the suggested integrated risk-layer approach may provide one piece of the puzzle for more integrated and holistic risk management approaches.

Acknowledgements We acknowledge funding for this research by the Austrian Climate Research Program 11, MacroMode project, project No KR18AC0K14602 and the EU Horizon 2020, RECEIPT project, grant agreement No 820712 .

Open Access This article is licensed under a Creative Commons Attribution 4.0 International License, which permits use, sharing, adaptation, distribution and reproduction in any medium or format, as long as you give appropriate credit to the original author(s) and the source, provide a link to the Creative Commons licence, and indicate if changes were made. The images or other third party material in this article are included in the article's Creative Commons licence, unless indicated otherwise in a credit line to the material. If material is not included in the article's Creative Commons licence and your intended use is not permitted by statutory regulation or exceeds the permitted use, you will need to obtain permission directly from the copyright 
holder. To view a copy of this licence, visit http://creativecommons. org/licenses/by/4.0/.

\section{References}

Andersen, T. 2011. Managing economic exposures of natural disasters: Exploring alternative financial risk management opportunities and instruments. IDB Publications (Working Papers) 2230. Washington, DC: Inter-American Development Bank. https://ideas.repec.org/p/idb/brikps/2230.html. Accessed 23 Aug 2021.

Aon. 2020. Weather, climate \& catastrophe insight: 2019 annual report. London: Aon.

Arias Carballo, D., J.J. Leiva, A. Sy, N. Traore, and F. Manfredi. 2013. Managing agricultural weather risks in the state of Santa Catarina, Brazil. Washington, DC: World Bank.

Ayyub, B.M., A.A. Pantelous, and J. Shao. 2016. Toward resilience to nuclear accidents: Financing nuclear liabilities via catastrophe risk bonds. ASCE-ASME Journal of Risk and Uncertainty in Engineering Systems, Part B: Mechanical Engineering 2(4): Article 041005.

Baral, S., C.H. Logie, A. Grosso, A.L. Wirtz, and C. Beyrer. 2013. Modified social ecological model: A tool to guide the assessment of the risks and risk contexts of HIV epidemics. BMC Public Health 13: Article 482.

Blair, D.V. 2009. Nurturing music learners in Mrs Miller's "family room": A secondary classroom for students with special needs. Research Studies in Music Education 31(1): 20-36.

Blöschl, G., J. Hall, A. Viglione, R.A.P. Perdigão, J. Parajka, B. Merz, D. Lun, B. Arheimer, et al. 2019. Changing climate both increases and decreases European river floods. Nature 573(7772): 108-111.

Botzen, W.W., O. Deschenes, and M. Sanders. 2019. The economic impacts of natural disasters: A review of models and empirical studies. Review of Environmental Economics and Policy 13(2): 167-188.

Boyland, M., F. Thomalla, L. Lebel, D. Marks, H. Kimkong, S.B. Tan, and A. Nugroho. 2019. Linking disaster recovery approaches and loss and damage systems in the Mekong region. In Development and climate change in the Mekong region: Case studies, ed. C. Krittasudthacheewa, H. Navy, B.D. Tinh, and S. Voladet, 169-188. Petaling Jaya, Malaysia: Strategic Information and Research Development Centre.

Bucher, A., A. Collins, B. Heaven Taylor, D. Pan, E. Visman, J. Norris, J.C. Gill, J. Rees, et al. 2020. New partnerships for codelivery of the 2030 agenda for sustainable development. International Journal of Disaster Risk Science 11(5): 680-685.

Bugmann, C. 1997. Proportional and non-proportional reinsurance: The main differences between these two types of reinsurance cover - A discussion with specific examples. Zurich: Swiss Reinsurance Company.

Burke, M., S.M. Hsiang, and E. Miguel. 2015. Global non-linear effect of temperature on economic production. Nature 527(7577): 235-239.

Carleton, T.A., and S.M. Hsiang. 2016. Social and economic impacts of climate. Science 353(6304): Article aad9837.

Carter, M., A. De Janvry, E. Sadoulet, and A. Sarris. 2014. Indexbased weather insurance for developing countries: A review of evidence and a set of propositions for up-scaling. Development Policies working paper, 111. France: Ferdi.

Centeno, M.A., M. Nag, T.S. Patterson, A. Shaver, and A.J. Windawi. 2015. The emergence of global systemic risk. Annual Review of Sociology 41: 65-85.
Cha, J., H.S. Park, D. Kim, H.J. Kim, M.J. Kim, Y.U. Cho, and M. Yun. 2018. A hierarchical prognostic model for risk stratification in patients with early breast cancer according to 18 f-fludeoxyglucose uptake and clinicopathological parameters. Cancer Medicine 7(4): 1127-1134.

Chantarat, S., C.G. Turvey, A.G. Mude, and C.B. Barrett. 2008. Improving humanitarian response to slow-onset disasters using famine-indexed weather derivatives. Agricultural Finance Review 68(1): 169-195.

Dawson, D., and K. McCulloch. 2005. Managing fatigue: It's about sleep. Sleep Medicine Reviews 9(5): 365-380.

Deubelli, T.M., and R. Mechler. 2021. Perspectives on transformational change in climate risk management and adaptation. Environmental Research Letters 16(5): Article 53002.

DiValli, J., and T. Perkins. 2020. "They know they're not coming back": Resilience through displacement in the riskscape of southwest Washington, DC. Cambridge Journal of Regions, Economy and Society 13(2): 363-380.

Dottori, F., W. Szewczyk, J.-C. Ciscar, F. Zhao, L. Alfieri, Y. Hirabayashi, A. Bianchi, I. Mongelli, et al. 2018. Increased human and economic losses from river flooding with anthropogenic warming. Nature Climate Change 8(9): 781-786.

Farvid, P., and V. Braun. 2018. "You worry, 'cause you want to give a reasonable account of yourself": Gender, identity management, and the discursive positioning of "risk" in men's and women's talk about heterosexual casual sex. Archives of Sexual Behavior 47(5): 1405-1421.

Froot, K. 2001. The market for catastrophe risk: A clinical examination. Cambridge, MA: National Bureau of Economic Research.

Garcia Azcarate, T., I. Bardaji, J. Viñas, I. Blanco-Gutiérrez, A. Garrido, and A. Felis. 2016. State of play of risk management tools implemented by member states during the period 2014-2020: National and European frameworks. Brussels: European Parliament.

Ghesquiere, F., and O. Mahul. 2010. Financial protection of the state against natural disasters: A primer. Policy Research Working Paper. Washington, DC: World Bank.

Giordano, P.C., and J.E. Copp. 2015. "Packages" of risk. Criminology \& Public Policy 14(1): 157-168.

Grossi, P., and H. Kunreuther. 2005. Catastrophe modeling: A new approach to managing risk (Vol. 25). Springer Science \& Business Media.

Hallegatte, S. 2015. The indirect cost of natural disasters and an economic definition of macroeconomic resilience. World Bank Policy Research Working Paper (7357). Washington, DC: World Bank.

Hallegatte, S., and V. Przyluski. 2010. The economics of natural disasters. CESifo Forum 11(2): 14-24.

Handmer, J., S. Hochrainer-Stigler, T. Schinko, F. Gaupp, and R. Mechler. 2020. The Australian wildfires from a systems dependency perspective. Environmental Research Letters 15(12): e121001.

Hochrainer-Stigler, S., and S. Hanger-Kopp. 2017. Subsidized drought insurance in Austria: Recent reforms and future challenges. Wirtschaftspolitische Blätter 6(4): 599-614.

Hochrainer-Stigler, S., and G. Pflug. 2012. Risk management against extremes in a changing environment: A risk-layer approach using copulas. Environmetrics 23(8): 663-672.

Hochrainer-Stigler, S., C. Colon, G. Boza, §. Brännström, J. Linnerooth-Bayer, G. Pflug, S. Poledna, E. Rovenskaya, and U. Dieckmann. 2020a. Measuring, modeling, and managing systemic risk: The missing aspect of human agency. Journal of Risk Research 23(10): 1301-1317.

Hochrainer-Stigler, S., C. Colon, G. Boza, S. Poledna, E. Rovenskaya, and U. Dieckmann. 2020b. Enhancing resilience of systems to 
individual and systemic risk: Steps toward an integrative framework. International Journal of Disaster Risk Reduction 51: 101868

Hochrainer-Stigler, S., T. Schinko, A. Hof, and P.J. Ward. 2021. Adaptive risk management strategies for governments under future climate and socioeconomic change: An application to riverine flood risk at the global level. Environmental Science \& Policy 125: 10-20.

IDB (Inter-American Development Bank). 2014. Disaster risk profile for Jamaica / Inter-American Development Bank (Technical note IDB-TN-635). Washington, DC: IDB.

IPCC (Intergovernmental Panel on Climate Change). 2012. Managing the risks of extreme events and disasters to advance climate change adaptation: Special report of the Intergovernmental Panel on Climate Change. Cambridge, UK: Intergovernmental Panel on Climate Change.

Koks, E.E., M. Bočkarjova, H. de Moel, and J.C.J.H. Aerts. 2015. Integrated direct and indirect flood risk modeling: Development and sensitivity analysis. Risk Analysis 35(5): 882-900.

Lamperti, F., V. Bosetti, A. Roventini, and M. Tavoni. 2019. The public costs of climate-induced financial instability. Nature Climate Change 9(11): 829-833.

Linnerooth-Bayer, J., and S. Hochrainer-Stigler. 2015. Financial instruments for disaster risk management and climate change adaptation. Climatic Change 133(1): 85-100.

Lucas, K., O. Renn, C. Jaeger, and S. Yang. 2018. Systemic risks: A homomorphic approach on the basis of complexity science. International Journal of Disaster Risk Science 9(3): 292-305.

Mahul, O., and J. Skees. 2007. Managing agricultural risk at the country level: The case of index-based livestock insurance in Mongolia. Washington, DC: World Bank.

Mechler, R., L.M. Bouwer, J. Linnerooth-Bayer, S. HochrainerStigler, J.C.J.H. Aerts, S. Surminski, and K. Williges. 2014. Managing unnatural disaster risk from climate extremes. Nature Climate Change 4(4): 235-237.

Mutius, E. von, and H.H. Smits. 2020. Primary prevention of asthma: From risk and protective factors to targeted strategies for prevention. The Lancet 396(10254): 854-866.

Naqvi, A., F. Gaupp, and S. Hochrainer-Stigler. 2020. The risk and consequences of multiple breadbasket failures: An integrated copula and multilayer agent-based modeling approach. OR Spectrum 42(3): 727-754.

OECD (Organization for Economic Co-operation and Development). 2003. Emerging systemic risks in the 21st century: An agenda for action. Paris: OECD.

Page, S.E. 2015. What sociologists should know about complexity. Annual Review of Sociology 41: 21-41.

Pflug, G.C., and A. Pichler. 2018. Systemic risk and copula models. Central European Journal of Operations Research 26(2): 465-483.

Phillips, T. 2020. The everyday politics of risk: Managing diabetes in Fiji. Medical Anthropology 39(8): 735-750.

Poledna, S., and S. Thurner. 2016. Elimination of systemic risk in financial networks by means of a systemic risk transaction tax. Quantitative Finance 16(10): 1599-1613.

Poledna, S., O. Bochmann, and S. Thurner. 2017. Basel III capital surcharges for G-SIBs are far less effective in managing systemic risk in comparison to network-based, systemic riskdependent financial transaction taxes. Journal of Economic Dynamics and Control 77: 230-246.

Poledna, S., S. Hochrainer-Stigler, M.G. Miess, P. Klimek, S. Schmelzer, J. Sorger, E. Shchekinova, E. Rovenskaya, et al. 2018. When does a disaster become a systemic event? Estimating indirect economic losses from natural disasters. https://arxiv. org/pdf/1801.09740. Accessed 23 Aug 2021.
Popp, A., S. Domptail, N. Blaum, and F. Jeltsch. 2009. Landuse experience does qualify for adaptation to climate change. Ecological Modelling 220(5): 694-702.

Reichstein, M., F. Riede, and D. Frank. 2021. More floods, fires and cyclones - Plan for domino effects on sustainability goals. Nature 592(7854): 347-349.

Reynolds, J. 2019. Gambling on big data: Designing risk in social casino games. European Journal of Risk Regulation 10(1): $116-131$.

Rose, A., and C.K. Huyck. 2016. Improving catastrophe modeling for business interruption insurance needs. Risk Analysis 36(10): 1896-1915.

Sadeghi, M., S. Hochrainer-Stigler, and M. Ghafory-Ashtiany. 2015. Evaluation of earthquake mitigation measures to reduce economic and human losses: A case study to residential property owners in the metropolitan area of Shiraz, Iran. Natural Hazards 78(3): 1811-1826.

Schinko, T., R. Mechler, and S. Hochrainer-Stigler. 2017. A methodological framework to operationalize climate risk management: Managing sovereign climate-related extreme event risk in Austria. Mitigation and Adaptation Strategies for Global Change 22(7): 1063-1086.

Schinko, T., R. Mechler, and S. Hochrainer-Stigler. 2019. The risk and policy space for loss and damage: Integrating notions of distributive and compensatory justice with comprehensive climate risk management. In Loss and damage from climate change, ed. R. Mechler, L.M. Bouwer, T. Schinko, S. Surminski, and J. Linnerooth-Bayer, 83-110. Cham: Springer International Publishing.

Schipper, E.L.F., F. Thomalla, G. Vulturius, M. Davis, and K. Johnson. 2016. Linking disaster risk reduction, climate change and development. International Journal of Disaster Resilience in the Built Environment 7(2): 216-228.

Shaw, R. 2020. Thirty years of science, technology, and academia in disaster risk reduction and emerging responsibilities. International Journal of Disaster Risk Science 11(4): 414-425.

Shi, P., T. Ye, Y. Wang, T. Zhou, W. Xu, J. Du, J. Wang, N. Li, et al. 2020. Disaster risk science: A geographical perspective and a research framework. International Journal of Disaster Risk Science 11(4): 426-440.

Stone, J.M. 1973. A theory of capacity and the insurance of catastrophe risks (Part I). The Journal of Risk and Insurance 40(2): Article 231.

UNDRR/CRED (United Nations Office for Disaster Risk Reduction / Centre for Research on the Epidemiology of Disasters). 2020. Human cost of disasters 2000-2019 report. Geneva/Brussels: UNDRR/CRED.

World Economic Forum. 2019. The global risks report 2019: 14th edn. Geneva: World Economic Forum.

World Economic Forum. 2021. The global risks report 2021: 16th edn. Geneva: World Economic Forum.

Yuan, H., Q.-Y. Ai, D.-W. Kwong, D.-T. Fong, A.D. King, V. Vardhanabhuti, V.-F. Lee, and P.-L. Khong. 2017. Cervical nodal volume for prognostication and risk stratification of patients with nasopharyngeal carcinoma, and implications on the tnm-staging system. Scientific Reports 7(1): Article 10387.

Zscheischler, J., O. Martius, S. Westra, E. Bevacqua, C. Raymond, R.M. Horton, B. van den Hurk, A. AghaKouchak, et al. 2020. A typology of compound weather and climate events. Nature Reviews Earth \& Environment 1(7): 333-347.

Zscheischler, J., S. Westra, B.J.J.M. van den Hurk, S.I. Seneviratne, P.J. Ward, A. Pitman, A. AghaKouchak, D.N. Bresch, et al. 2018. Future climate risk from compound events. Nature Climate Change 8(6): 469-477. 